\title{
Risk Analysis for Cascade Reservoirs Collapse Based on Bayesian Networks under the Combined Action of Flood and Landslide Surge
}

\author{
Ping Li and Chuan Liang \\ College of Water Conservancy and Hydropower Engineering, Sichuan University, Chengdu 610065, China \\ Correspondence should be addressed to Chuan Liang; lchester@sohu.com
}

Received 7 August 2016; Revised 16 October 2016; Accepted 7 November 2016

Academic Editor: Gerardo Severino

Copyright (C) 2016 P. Li and C. Liang. This is an open access article distributed under the Creative Commons Attribution License, which permits unrestricted use, distribution, and reproduction in any medium, provided the original work is properly cited.

\begin{abstract}
A method based on a Bayesian network (BN) combined with stochastic Monte Carlo (MC) simulation is used in this research to calculate the probability and analyze the risk of a single reservoir dam overtopping and two reservoirs collapsing under the combined action of flood and landslide surge. Two adjacent cascade reservoirs on the Dadu River are selected for risk calculation and analysis. The results show that the conditional probability of a dam overtopping due to flooding in a single reservoir is relatively small; the conditional probability of a dam overtopping due to landslide surge in a single reservoir is relatively large; a combination of flooding and landslide surge greatly increases the risk of the dam overtopping. The conditional probability that the dam in (downstream) Changheba reservoir overtops as a result of a dam-break flood from (upstream) Houziyan reservoir is greater than 0.8 when the water in Changheba reservoir is at its normal level. Under the combined action of flooding and landslide surges, the joint probability that the two cascade reservoirs collapse in a variety of typical situations is very small.
\end{abstract}

\section{Introduction}

According to the available statistics, over half of the cases of embankment dam break are caused by a dam overtopping; that is, dam overtopping is the main reason that dam breaks occur. As is well known, flooding is a major factor that may result in dam overtopping. In addition, a landslide into a reservoir can arouse a huge surge which may also lead to dam overtopping. If these two factors (flooding and landslide surge) occur at the same time, then it may be expected that the risk of the dam overtopping will be greatly increased. There have been many studies aimed at analyzing the risk that a dam will overtop due to flooding, but little has been done in respect of landslide surge. Stochastic models have been established for flood risk analysis and compared with a Bayes method [1]. Another approach used was to analyze the mechanism responsible for dam failure from the point of view of hydraulics [2]. The latter authors used an integration method to directly calculate the probability of the dam overtopping. Other scholars have used (several) other different methods to calculate and analyze landslide surges in the Three Gorges Reservoir [3]. An ISPH model has also been used to simulate landslide surges in a reservoir and the subsequent process of a dam overtopping [4].

In recent years, Bayesian networks (BNs) have been one of the most successful artificial intelligence methods used to deal with uncertainty. For example, they have been used to analyze the reliability and risk management of earthquake disasters [5]. Other researchers have used BNs to study the risk assessment surrounding warship retirement [6], proposed BNs to model the risk of natural disasters [7], and discussed the application of BNs to the analysis of fire risk [8].

As far as dam overtopping is concerned, the BN studies undertaken so far mostly encompass just a single factor that may cause a dam to overtop; there are hardly any risk analyses for dam overtopping which consider the combined action of flooding and landslide surges. In addition, the BN studies aimed at analyzing the risk of dam overtopping must be considered as preliminary attempts. Such risk analyses only encompass a single reservoir (or a single system) without giving consideration to multiple-reservoir collapse. To date, there is still very little research in the literature focusing on 


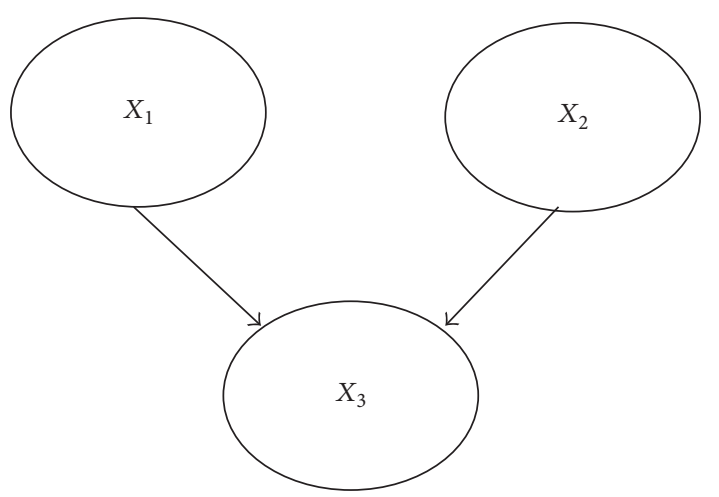

Figure 1: A “ $V$ ”-type Bayesian network.

analyzing the risk of collapse of multiple reservoirs using BNs. Therefore, this study is based on BN theory and aims to establish a BN model to calculate the probability of collapse for two reservoirs under the combined action of flooding and landslide surge. One notable feature of the work is that a stochastic Monte Carlo (MC) simulation method is used to estimate the probability of each node event in the $\mathrm{BN}$ structures. We also consider some examples to show the effectiveness of the combined BN/MC method as applied to analyzing the risk of reservoir collapse.

\section{Methods}

2.1. Bayesian Networks. A Bayesian network is a conditional probability table that contains a directed acyclic graph model and a complex joint-probability distribution of the compact representation. A BN can be used to express and analyze the uncertainty or probability of events and allows one to make inferences using incomplete or uncertain knowledge and information. A BN assigns the joint-probability distribution for $n$ random variables $X=\left\{X_{1}, X_{2}, \ldots, X_{n}\right\}$. The $\mathrm{BN}$ is expressed via its conditional independence and conditional probability relationships and the joint-probability distribution can be written in the compact form:

$$
\begin{aligned}
P\left(X_{1}, X_{2}, \ldots, X_{n}\right) & =\prod P\left(X_{i} \mid \pi_{X_{i}}\right) \\
P\left(X_{i}\right) & =\sum P\left(\pi_{X_{i}}\right) P\left(X_{i} \mid \pi_{X_{i}}\right) .
\end{aligned}
$$

As an example, for the network diagram shown in Figure 1, the joint probability is

$$
\begin{aligned}
P\left(X_{1}, X_{2}, X_{3}\right)= & P\left(X_{1}\right) P\left(X_{2}\right) P\left(X_{3} \mid X_{1}, X_{2}\right), \\
P\left(X_{3}\right)= & P\left(X_{1}\right) P\left(X_{3} \mid X_{1}\right) \\
& +P\left(X_{2}\right) P\left(X_{3} \mid X_{2}\right) .
\end{aligned}
$$

The Bayesian formula indicates that

$$
P\left(\pi_{X_{i}} \mid X_{i}\right)=\frac{P\left(X_{i}\right) P\left(X_{i} \mid \pi_{X_{i}}\right)}{\sum_{j=1}^{n} P\left(X_{j}\right) P\left(X_{j} \mid \pi_{X_{j}}\right)},
$$

where $P\left(X_{1}, X_{2}, \ldots, X_{n}\right)$ is the joint probability, $P\left(X_{i}\right)$ is the prior probability, $P\left(X_{i} \mid \pi_{X_{i}}\right)$ is the conditional probability, and $P\left(\pi_{X_{i}} \mid X_{i}\right)$ is the posterior probability.

2.2. Establishing the BN Model. Suppose that there are two adjacent cascade reservoirs $A$ and $B$. In addition to flooding, landslide surges may also occur and pose a risk of causing dam overtopping to a single reservoir. That is, these two factors together constitute the causes leading to a single reservoir dam overtopping. For two adjacent reservoirs, in addition to flooding and landslide surge, dam-break flooding from upstream reservoir $A$ is another main factor that can lead to the dam overtopping in downstream reservoir $B$. That is, these three factors together constitute the causes of the dam in reservoir $B$ overtopping. As dam overtopping is a crucial factor that can result in an earth-rock dam break, it can be considered that "dam overtopping" means the same as "dam break." Therefore, in this study, the effects of other factors, for example, failure of the structure of the dam, are not considered.

The BN structure for two reservoirs collapsing under the combined action of flooding and landslide surge is shown in Figure 2(a). According to the conditional independence of the $\mathrm{BN}$, the reason that dam break in reservoir $A$ has a direct effect on reservoir $B$ is only via the dam-break flood. Thus, all the causal nodes resulting in dam break in reservoir $A$ can be condensed down to one causal node (dam-break flood). Subsequently, the BN structure can also have the form shown in Figure 2(b). The definitions of the various parameters appearing in the BNs are given in "Abbreviations."

According to the BN structures described above we have the following.

For a single reservoir,

$$
\begin{aligned}
P\left(O_{A}\right) & =P\left(F_{O}\right) \\
& =P\left(F_{A}\right) P\left(O_{A} \mid F_{A}\right)+P\left(S_{A}\right) P\left(O_{A} \mid S_{A}\right), \\
P\left(O_{B}\right) & =P\left(F_{A}\right) P\left(O_{A} \mid F_{A}\right)+P\left(S_{A}\right) P\left(O_{A} \mid S_{A}\right) .
\end{aligned}
$$

For two reservoirs,

$$
\begin{aligned}
& P\left(O_{B}\right) \\
& =P\left(F_{B}\right) P\left(O_{B} \mid F_{B}\right)+P\left(S_{B}\right) P\left(O_{B} \mid S_{B}\right) \\
& \quad+P\left(F_{O}\right) P\left(O_{B} \mid F_{O}\right), \\
& P\left(F_{A} S_{A} F_{O} F_{B} S_{B} O_{B}\right)=P \\
& \quad=P\left(F_{A}\right) P\left(S_{A}\right) P\left(F_{B}\right) P\left(F_{O}\right) P\left(S_{B}\right) P\left(O_{B}\right) .
\end{aligned}
$$

\subsection{Probability of Overtopping due to Flooding}

2.3.1. Probability of Flooding. In China, it is generally believed that the peak flow obeys a type P-III probability distribution. Our main calculation method is based on observed flood data and uses the moment method to estimate statistical parameters for the mean, $\bar{x}$, coefficient of variation $\left(C_{v}\right)$, and coefficient of skewness $\left(C_{s}\right)$. The data was fitted to the P-III 


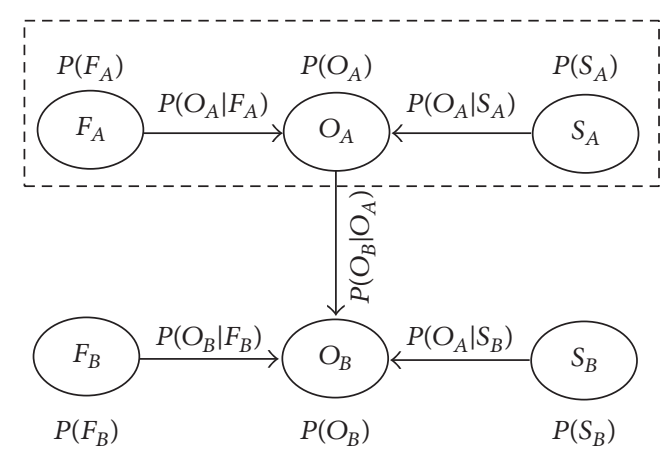

(a)

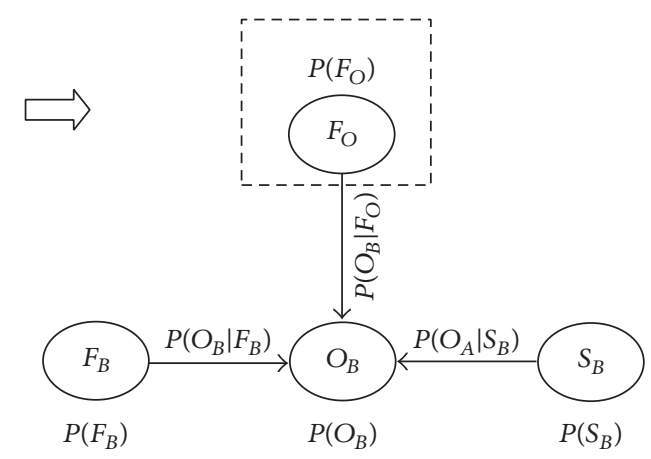

(b)

FIGURE 2: BN structures for two-reservoir collapse.

distribution curve using eye-estimation, and the probabilities that the peak flows occurred were obtained. That is, the values of $P\left(F_{A}\right)$ and $P\left(F_{B}\right)$ were derived.

\subsubsection{Conditional Probability of Overtopping due to Flooding}

(1) Stochastic Method of Simulating Flood Peak Flows. Here, we use an acceptance-rejection sampling method based on stochastic Monte Carlo simulation to estimate the value of the conditional probabilities $P\left(O_{A} \mid F_{A}\right)$ and $P\left(O_{B} \mid F_{B}\right)$. The acceptance-rejection method is applied to convert the P-III type probability distribution function. Thus, we have

$$
x_{t}=a_{0}+\frac{1}{\beta}\left(1-\sum_{k=1}^{[\alpha]} \ln \xi_{t k}-B_{t} \ln \xi_{[\alpha]+3}\right) \text {, }
$$

where $\alpha, \beta$, and $a_{0}$ are three parameters that are used to describe the P-III type curve. During the simulation, we let $t=1,2, \ldots, N$, so that $N$ purely random values are generated which obey the P-III type distribution using random number generation.

(2) Calculation of $P\left(O_{A} \mid F_{A}\right)$ and $P\left(O_{B} \mid F_{B}\right)$. For reservoirs $A$ and $B$, the Monte Carlo method is used to simulate $N_{A}$ and $N_{B}$ peak flow data points, respectively. Then, by amplifying the typical flood hydrograph using the same magnification, we can get the $N_{A}$ and $N_{B}$ flood hydrographs. The reservoir capacity and discharge flow curves are combined. Using these and the flood hydrographs, we can obtain $N_{A}$ and $N_{B}$ highest water levels in front of the dam according to the reservoir dispatching rules for flood routing through the reservoir. The number of times $\left(m_{A}, m_{B}\right)$ wherein the water level exceeds the height of the dam in $N_{A}$ and $N_{B}$ highest water levels is counted, respectively. The value of $m / N$ can be considered to be the conditional probability of the dam overtopping (or, alternatively, the dam break) due to flooding. That is, $P\left(O_{A} \mid\right.$ $\left.F_{A}\right)=m_{A} / N_{A}$, and $P\left(O_{B} \mid F_{B}\right)=m_{B} / N_{B}$.

2.4. Probability of Overtopping due to Landslide Surge. If the slope of a reservoir bank has poor stability, it may slide under the disturbing action of an earthquake or heavy rain. A landslide often provokes a huge surge, which may, in turn, lead to the dam overtopping. Therefore, if we want to calculate the conditional probability of a dam overtopping due to landslide surge, the first thing we need to do is calculating and analyzing the stability of the slope. Here, we assume that the probability of a landslide occurring is equal to the probability of a landslide surge occurring. Then, we can calculate the conditional probability of the dam overtopping due to a landslide surge according to the calculated probability of a landslide surge occurring combined with a stochastic MC simulation.

2.4.1. Calculation of the Stability with respect to Landslide. Landslide stability is generally measured by the coefficient of stability $K$. If $K>1$, it indicates that the slope is relatively stable, and landslide will not occur. If $K<1$, the opposite is true.

In this work, the Bishop method is adopted to calculate the landslide stability coefficient. Ignoring the effect of pore water pressure, the stability coefficient is given by

$$
\begin{aligned}
K & =\frac{\sum_{i=1}^{r}\left(1 / m_{\alpha_{i}}\right)\left[c b_{i}+W_{i} \tan \varphi\right]}{\sum_{i=1}^{r} W_{i} \sin \alpha_{i}}, \\
m_{\alpha_{i}} & =\cos \alpha_{i}+\frac{\tan \varphi}{K} \sin \alpha_{i},
\end{aligned}
$$

where $\alpha_{i}, b_{i}$, and $W_{i}$ are, respectively, the average slope angle, width, and weight of the $i$ th soil slice, $r$ is the total number of slices, $c$ is the cohesion, and $\varphi$ is the internal friction angle.

2.4.2. Calculation of the Landslide Surge. Sliding velocity has a great impact on a landslide surge. Therefore, the first step in the landslide surge calculation is to calculate the sliding velocity of the landslide.

(1) Sliding Velocity. Of the various methods available to calculate the landslide sliding velocity, the energy method is the most widely used method and the concepts involved are clear. The sliding velocity $(V)$ is given by

$$
V=\sqrt{2 g h} \cdot \sqrt{1-\cot \alpha \cdot \tan \varphi-\frac{c L}{M g \sin \alpha}} .
$$


In this expression, $g$ is the acceleration due to gravity $\left(9.8 \mathrm{~m} / \mathrm{s}^{2}\right), h$ is the height of the center of gravity of the landslide body with respect to the surface of the water in the reservoir (m), $\alpha$ is the average dip angle of the sliding surface $\left({ }^{\circ}\right), c$ is the cohesion $(\mathrm{kPa}), \varphi$ is the internal friction angle $\left(^{\circ}\right)$, $L$ is the length of the landslide body (m), and $M$ is the mass of the landslide body $(\mathrm{kg})$.

(2) Landslide Surge. After comparing several different methods (including the American Society of Civil Engineers recommended method, the method of the China Institute of Water Resources and Hydropower Research, and the Panjiazheng method), Hu et al. pointed out that the Panjiazheng method is relatively consistent with the actual situation [3]. This method is therefore adopted here to calculate the landslide surge occurring in the reservoir.

The surge height on the other side of a landslide, $\eta(\mathrm{m})$, is given by

$$
\begin{aligned}
\eta & =2 \frac{\eta_{0}}{\pi}(1+k) \sum_{n=1,3,5, \ldots}^{n}\left\{k^{2(n-1)}\right. \\
& \left.\cdot \ln \left[\frac{l}{(2 n-1) B}+\sqrt{1+\left[\frac{l}{(2 n-1) B}\right]^{2}}\right]\right\}
\end{aligned}
$$

and the surge height in front of the dam, $\eta_{x}(\mathrm{~m})$, is given by

$$
\begin{aligned}
\eta_{x} & =\frac{\eta_{0}}{\pi} \sum_{n=1,3,5, \ldots}^{n}\left(1+k \cos \theta_{n}\right) k^{(n-1)} \\
\cdot \ln & {\left[\frac{\sqrt{1+\left(n B /\left(x_{0}-L\right)\right)^{2}}-1}{\left(x_{0} /\left(x_{0}-L\right)\right) \sqrt{1+\left(n B / x_{0}\right)^{2}}-1}\right], }
\end{aligned}
$$

where $\eta_{0}$ is the initial surge height caused by the landslide $(\mathrm{m}), k$ is the wave reflection coefficient $(k \approx 1), l=L / 2$ is the half length of the landslide along the bank $(\mathrm{m}), B$ is the average breadth of reservoir's water surface $(\mathrm{m})$, and $x_{0}$ is the distance from the calculation point to the landslide $(\mathrm{m})$.

The angles $\theta_{n}$ are given by

$$
\begin{aligned}
& \tan \theta_{1}=\frac{x_{0}}{B}, \\
& \tan \theta_{3}=\frac{x_{0}}{3 B}, \\
& \tan \theta_{n}=\frac{x_{0}}{n B} .
\end{aligned}
$$

2.4.3. Calculation of the Probability of a Dam Overtopping due to Landslide Surge. As a result of the perturbation from external factors, the cohesion $(c)$, internal friction angle $(\varphi)$, and weight $(W)$ of the landslide will be uncertain; that is, they should be viewed as random variables. Hence, the values of the stability coefficient $(K)$ and sliding velocity $(V)$ are also uncertain. In view of this, we use a stochastic Monte Carlo method to simulate these random variables in order to obtain values for $K$ and $V$. Then, the prior probability of a landslide

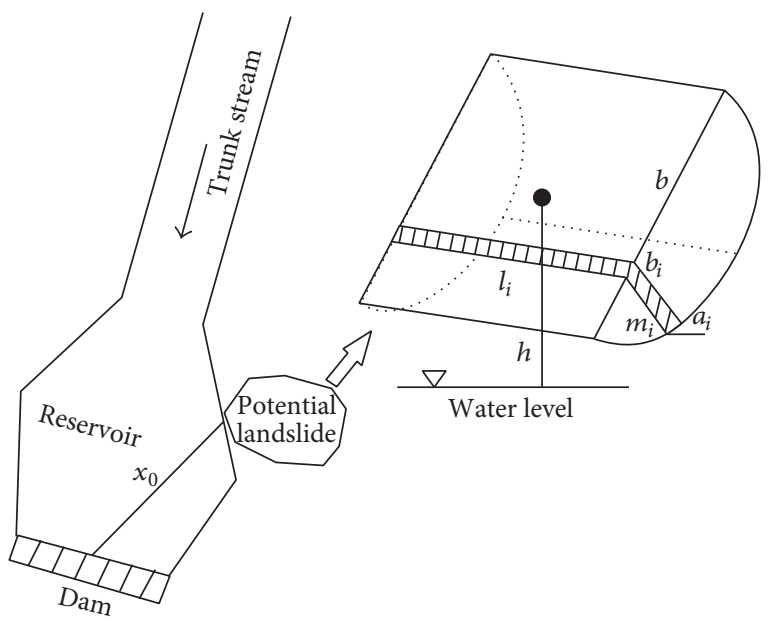

FIGURE 3: A simple analysis model for the landslide surge simulations.

surge occurring and the conditional probability of the dam overtopping due to the landslide surge can be computed according to the simulation results. The assumptions made and simulation steps involved are as follows.

(1) Assume that there is a potential landslide at a distance $x_{0}$ from the dam. The breadths of the landslide $(b)$ and landslide height $h$ are random variables that obey normal distributions. The breadth of each soil slice of the landslide in the vertical direction is divided into $1 \mathrm{~m}$ pieces; that is, the total number of soil slices is $b$.

(2) Assume that the length $\left(l_{i}\right)$, thickness $\left(t_{i}\right)$, slope angle $\left(\alpha_{i}\right)$, cohesion $\left(c_{i}\right)$, and internal friction angle $\left(\varphi_{i}\right)$ of soil slice $i$ are all random variables which obey normal distributions. We also have $W_{i}=l_{i} t_{i} \gamma$, where $\gamma$ is the volumetric weigh of the soil. Figure 3 shows a simple model used in the simulation analysis.

(3) Following the $\mathrm{MC}$ method, $N$ group random numbers obeying a normal distribution were obtained after $N$ simulations for each random variable (the calculations here were performed using MATLAB ${ }^{\mathrm{TM}}$ ). Then, the $N$ group random numbers were substituted into the formulae for $K$ and $\eta_{x}$ to give $N$ values of $K$ and $\eta_{x}$. The number of $K$ values less than 1 was counted as was the number of the values of $\eta_{x}$ that exceeded the dam height when added to the reservoir water level. This yielded values for $m_{K}$ and $m_{\eta}$, respectively. Finally, the probabilities $P\left(S_{A}\right)$ (or $\left.P\left(S_{B}\right)\right)=m_{K} / N$ and $P\left(O_{A} \mid S_{A}\right)$ (or $\left.P\left(O_{B} \mid S_{B}\right)\right)=m_{\eta} / N$ were determined.

2.5. Conditional Probability of a Dam Overtopping due to a Dam-Break Flood. The risk analysis for the occurrence of the dam overtopping in (downstream) reservoir $B$ due to a dambreak flood from (upstream) reservoir $A$ involves two main processes: (i) the dam break in reservoir $A$ itself and (ii) flood routing of the dam break from reservoir $A$ to reservoir $B$. We consider each in turn.

\subsubsection{The Dam-Break Process in Upstream Reservoir A}

(1) Dam Break Maximum Flow. We consider the worst case scenario; that is, the dam undergoes instantaneous failure. 


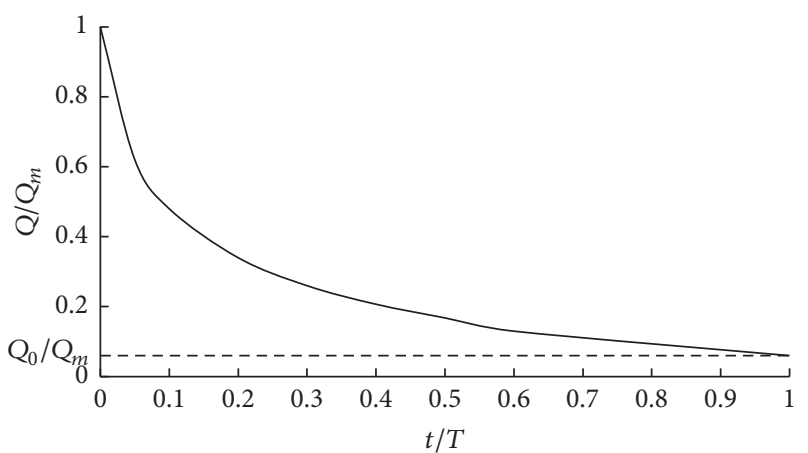

Figure 4: A typical profile for the flow resulting from an instantaneous dam-break flood $\left(Q_{0}\right.$ is the inflow before dam break, $Q_{m}$ is the dam break maximum flow, and $T=5 \mathrm{~V} / \mathrm{Q}_{m}$, where $V$ is the maximum capacity).

The maximum flow $Q_{m}$ can be found using the Xierenzhi formula [9]:

$$
\begin{aligned}
Q_{m}=\lambda B \sqrt{g} H_{0}^{1.5}, & \\
\lambda & \lambda=m^{m-1}\left[\frac{2 \sqrt{m}+v_{0} / \sqrt{g H_{0}}}{1+2 m}\right]^{2 m+1} .
\end{aligned}
$$

In these expressions, $B$ is the dam crest length $(\mathrm{m}), H_{0}$ is the water depth in front of the dam (m), $\lambda$ is a traffic parameter, $M$ is the valley cross section shape index, and $v_{0}$ is the average flow velocity in the channel before dam break $(\mathrm{m} / \mathrm{s})$.

(2) Dam Flood Process. This consists of three parts: (i) reservoir discharge before dam break, (ii) flow during dam break, and (iii) natural runoff after the reservoir discharge ends. The shape of the instantaneous dam-break flood process is akin to four parabolic processes [10] (Figure 4).

2.5.2. Flood Routing Process. The routing process of a dambreak flood from an upstream to a downstream reservoir can be enumerated using the Muskingum method [11]:

$$
\begin{aligned}
Q_{2} & =C_{0} I_{2}+C_{1} I_{1}+C_{2} Q_{1}, \\
C_{0}+C_{1}+C_{2} & =1, \\
C_{0} & =\frac{0.5 \Delta t-T x}{T-T x+0.5 \Delta t}, \\
C_{1} & =\frac{0.5 \Delta t+T x}{T-T x+0.5 \Delta t}, \\
C_{2} & =\frac{T-T x-0.5 \Delta t}{T-T x+0.5 \Delta t},
\end{aligned}
$$

where $I_{1}$ and $I_{2}$ are the upper-section flow $\left(\mathrm{m}^{3} / \mathrm{s}\right)$ at the beginning and end of the process, respectively, $Q_{1}$ and $Q_{2}$ are the lower-section flow $\left(\mathrm{m}^{3} / \mathrm{s}\right)$ at the beginning and end of the process, respectively, $\Delta t$ is the time step used (s), $T$ is the propagation time of the flood in the reach of the river under steady flow (s), and $x$ is the tank storage coefficient.
2.5.3. Calculation of $P\left(O_{B} \mid F_{O}\right)$. Suppose reservoir $A$ is put into $X$ different water level conditions which cause dam break to occur. Then, $X$ maximum flood peak flows can be obtained after the dam-break flood routes to the downstream reservoir $B$ by using the Muskingum method. Assume that this peak flow series obeys a P-III distribution, then, to calculate the statistical parameters (mean $(\bar{x})$, coefficient of variation $\left(C_{v}\right)$, and coefficient of skewness $\left(C_{s}\right)$ ) from the flood series, combined with a Monte Carlo method for stochastic simulation to get $N$ peak flow data points, and $N$ flood hydrographs will be obtained after amplifying the selected typical flood hydrograph. Finally, in accordance with the capacity and discharge curves and the flood dispatching rules of the downstream reservoir $B$, the $N$ highest water levels in front of the dam can be calculated according to the reservoir flood regulating calculation. If there are $m$ highest water levels in front of the dam that exceed the dam height of reservoir $B$, then $m / N$ can be considered to be the conditional probability of the dam overtopping in reservoir $B$ due to a dam-break flood from upstream reservoir $A$; that is, $P\left(O_{B}\right.$ | $\left.F_{O}\right)=m / N$.

\section{Results and Discussion}

3.1. Project Overview. The Houziyan and Changheba reservoirs are adjacent in the Dadu River trunk stream in Sichuan, China, and will be analyzed using our method. The river from the Houziyan to Changheba reservoirs runs through mountainous terrain in deep ravines. Deep, narrow valleys contain water that is fast-flowing and, thus, complex.

Houziyan Hydropower Station is located in Kangding County, Sichuan. It forms a 9-cascade hydropower station on the Dadu River which is subjected to 22 development program recommendations. The reservoir's dam is an embankment dam, and the dam site above the controlled river basin area covers $54,036 \mathrm{~km}^{2}$. The design standard for the reservoir is $P=0.1 \%$ and the checking standard is the probable maximum flood (PMF). The design flood level is $1841.55 \mathrm{~m}$, the flood check level is $1845.41 \mathrm{~m}$, and the normal storage level is $1842 \mathrm{~m}$. The dam's total capacity is 706 million $\mathrm{m}^{3}$ and the normal storage level capacity is 662 million $\mathrm{m}^{3}$. The dam crest elevation is $1848.5 \mathrm{~m}$, the dam is $223.5 \mathrm{~m}$ high, and the crest length of the dam is $283 \mathrm{~m}$. The dead level is $1802.00 \mathrm{~m}$ and the regulating capacity is 3.87 million $\mathrm{m}^{3}$, with seasonal regulation of performance applied.

Changheba Hydropower Station is a 10-cascade hydropower station on the Dadu River scheme which is downstream of the Houziyan Hydropower Station. The site is located in Kangding County, Sichuan. It is located on the trunk stream of Dadu River about 4-7 km below the Jintang river estuary. The reservoir dam is an embankment dam. The river basin area above the dam site measures $56,648 \mathrm{~km}^{2}$, accounting for $73.2 \%$ of the total basin area. Its design standard is $P=0.1 \%$ and the checking standard is the PMF. The design flood level is $1690 \mathrm{~m}$, the checking flood level is $1694.6 \mathrm{~m}$, and the normal storage level is $1690 \mathrm{~m}$. The total capacity is 1.075 billion $\mathrm{m}^{3}$, the normal storage level capacity is 1.015 billion $\mathrm{m}^{3}$, and the regulating capacity is 4.15 million $\mathrm{m}^{3}$. The dam crest elevation is $1697 \mathrm{~m}$, the dam height 
TABLE 1: Designed flood results for the Houziyan and Changheba reservoirs.

\begin{tabular}{|c|c|c|c|c|c|c|}
\hline \multirow{2}{*}{ Reservoir } & \multicolumn{3}{|c|}{ Statistical parameter } & \multicolumn{3}{|c|}{ Designed value } \\
\hline & Mean $\left(\mathrm{m}^{3} / \mathrm{s}\right)$ & $C_{v}$ & $C_{s} / C_{v}$ & Criterion & $P$ & Value $\left(\mathrm{m}^{3} / \mathrm{s}\right)$ \\
\hline \multirow{2}{*}{ Houziyan } & \multirow{2}{*}{3300} & \multirow{2}{*}{0.26} & \multirow{2}{*}{5} & Check & PMF & 9940 \\
\hline & & & & Design & $0.1 \%$ & 7550 \\
\hline \multirow{2}{*}{ Changheba } & \multirow{2}{*}{3550} & \multirow{2}{*}{0.24} & \multirow{2}{*}{5} & Check & PMF & 10400 \\
\hline & & & & Design & $0.1 \%$ & 7650 \\
\hline
\end{tabular}

TABLE 2: Simulation parameters and calculated probabilities.

\begin{tabular}{lcccccccc}
\hline Reservoir & $\begin{array}{c}\text { Simulation } \\
\text { time, } N\end{array}$ & $\begin{array}{c}\text { Probability } \\
\text { interval, } \Delta P\end{array}$ & $\begin{array}{c}\text { Adjusted water } \\
\text { level }\end{array}$ & $\begin{array}{c}\text { Water level over } \\
\text { dam (times), } m\end{array}$ & $\begin{array}{c}\text { Dam overtopping } \\
\text { frequency, } P=m / N\end{array}$ & $\begin{array}{c}\text { Overtopping probability } \\
\text { Probability }\end{array}$ & $\Delta P * P$ \\
\hline \multirow{2}{*}{ Houziyan } & 1000 & $0 \sim 0.0001$ & Normal & 1842 & 17 & 0.017 & $P\left(O_{A} \mid F_{A}\right)$ & $1.70 \times 10^{-6}$ \\
& 1000 & $0 \sim 0.0001$ & Check & 1845.41 & 21 & 0.021 & $P\left(O_{A} \mid F_{A}\right)$ & $2.10 \times 10^{-6}$ \\
\multirow{3}{*}{ Changheba } & 1000 & $0 \sim 0.0001$ & Normal & 1690 & 14 & 0.014 & $P\left(O_{B} \mid F_{B}\right)$ & $1.40 \times 10^{-6}$ \\
& 1000 & $0 \sim 0.0001$ & Check & 1694.6 & 17 & 0.017 & $P\left(O_{B} \mid F_{B}\right)$ & $1.70 \times 10^{-6}$ \\
\hline
\end{tabular}

TABLE 3: Statistical parameters for the random variables.

\begin{tabular}{|c|c|c|c|c|c|c|c|}
\hline Parameter & $l_{i}(\mathrm{~m})$ & $t_{i}(\mathrm{~m})$ & $c(\mathrm{kPa})$ & $\varphi\left(^{\circ}\right)$ & $\alpha_{i}\left(^{\circ}\right)$ & $r$ & $h(\mathrm{~m})$ \\
\hline Mean & 1500 & 20 & 35 & 35 & 45 & 150 & 30 \\
\hline Standard deviation & 880 & 12 & 5 & 4.5 & 27 & 85 & 18 \\
\hline
\end{tabular}

TABLE 4: Calculated prior probabilities for the occurrence of a landslide surge.

\begin{tabular}{lccccc}
\hline $\begin{array}{l}\text { Dam-landslide } \\
\text { distance, } x_{0}(\mathrm{~km})\end{array}$ & \multicolumn{2}{c}{ Soil-slice parameter } & \multicolumn{3}{c}{ Simulation and calculation results } \\
Width, $b_{i}(\mathrm{~m})$ & $\begin{array}{c}\text { Volumetric weight, } \gamma \\
\left(\mathrm{kN} / \mathrm{m}^{3}\right)\end{array}$ & $\begin{array}{c}\text { Simulation time, } \\
\text { Number of times } \\
K<1, m_{K}\end{array}$ & $\begin{array}{c}\text { Landslide surge probability, } \\
P\left(S_{A}\right) / P\left(S_{B}\right)\end{array}$ \\
\hline 3 & 1 & 20 & 10000 & 387 & 0.0387 \\
\hline
\end{tabular}

is $240 \mathrm{~m}$, and its crest length is $497.94 \mathrm{~m}$. The river channel from the Houziyan reservoir to the downstream Changheba reservoir is about $50 \mathrm{~km}$ long.

3.2. Risk Analysis for a Single Reservoir Overtopping due to Flooding. The statistical parameters relating to the inflow flood peak series for the Houziyan reservoir and the interval flood peak series for the Changheba reservoir are shown in Table 1 together with the corresponding design values.

After selecting an appropriate probability range for the simulations and calculations, the conditional probabilities of flooding leading to dam overtopping for different reservoir water levels were obtained (according to the methods outlined above for calculating the probability of peak floods occurring and conditional probability of flooding leading to dam overtopping). The simulation parameters and results of the probability calculations are shown in Table 2.

The results shown in Table 2 indicate that the conditional probability that flooding will result in the dam overtopping in either of the two reservoirs is of the order of $10^{-6}$. This shows that the risk of flooding leading to a single reservoir dam overtopping is very small. It also shows that the difference between the risks for the two reservoirs is small. It is also apparent that the higher the water level in a reservoir, the greater the risk of the dam overtopping due to flooding.

3.3. Risk Analysis for a Single Reservoir Overtopping due to Landslide Surge. With reference to landslide investigations in the Dadu River basin (and other related literature), values were determined for the statistical parameters of each random variable (Table 3 ). Then, 10,000 MC simulations were made (using MATLAB software) to calculate the stability coefficients and other characteristics of the landslide surge. Subsequently, the prior probability that a landslide surge will occur and the conditional probability that the dam will overtop due to the landslide surge were calculated for different water levels in the reservoir. The parameters and simulation results are shown in Tables 4 and 5 .

The results in Tables 4 and 5 indicate that the prior probability of occurrence of a landslide (surge) in the reservoir is 0.0387. The conditional probability that the dam will overtop due to a landslide surge when either the Houziyan reservoir or Changheba reservoir is at normal or check water level is about 0.2. Clearly, landslide surge has a relatively large risk of leading to dam overtopping compared to flooding. In addition, the higher the water level in the reservoir is, the larger the conditional probability that a landslide surge will lead to dam overtopping; that is, the risk of dam overtopping is greater. 


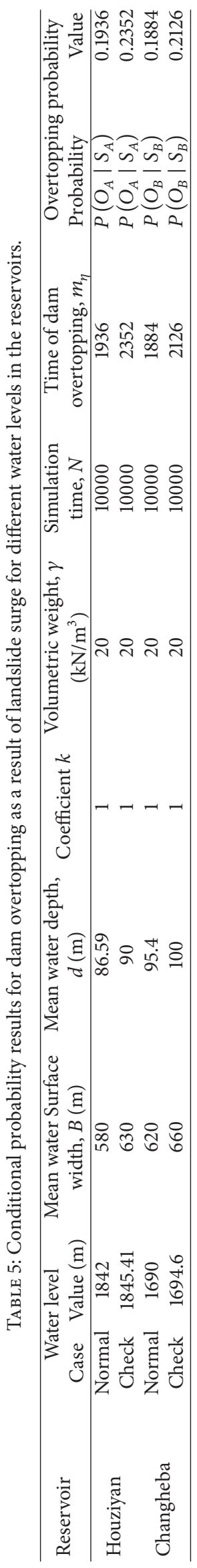




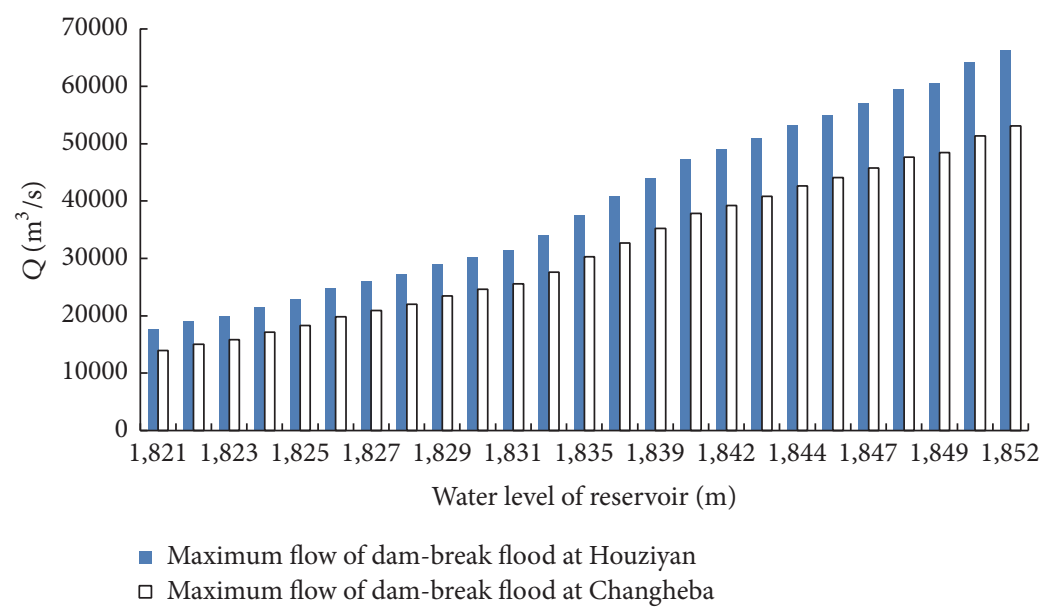

FIgURE 5: Maximum flows associated with the dam-break flood (at the Houziyan reservoir and after routing to the Changheba reservoir).

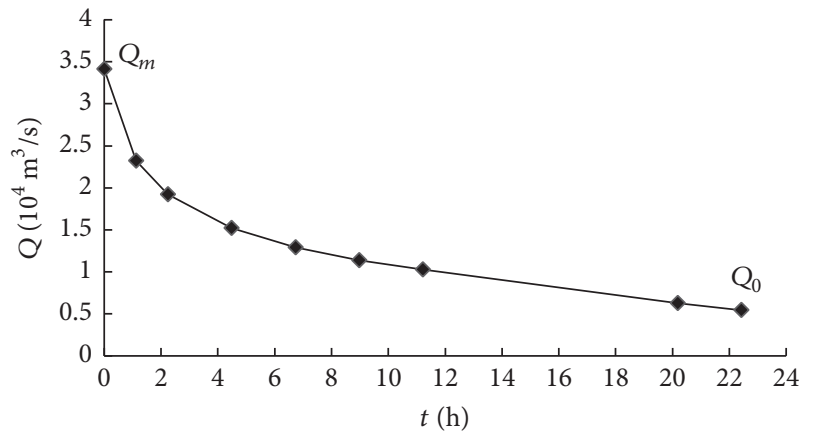

Figure 6: Typical process line for an instantaneous dam-break flood at the Houziyan reservoir.

\subsection{Risk Analysis for Dam Overtopping due to Dam-Break Flooding}

\subsubsection{Dam-Break Flooding Process}

(1) Dam-Break Flood Maximum Flows. We assume that the Houziyan reservoir undergoes a dam break under the action of excessive flooding. The calculated maximum flows are shown in Figure 5.

(2) Dam-Break Flow. A profile can be drawn to illustrate the typical flow process resulting from a dam break (Figure 6) based on the maximum flow results for a dam-break flood given above and the generalized flooding profile for an instantaneous dam break. In addition, by combining the upstream flow process from the Houziyan reservoir and the discharge process during reservoir flood regulation, more comprehensive flood profiles, before and after dam break, can be constructed, as shown in Figure 7.

(3) Dam-Break Flood Routing. The Muskingum method can now be used to calculate the flood routing process based on the flooding process lines before and after dam break at the Houziyan reservoir. Then, the maximum flows and
TABLE 6: Calculation parameters for the Muskingum method.

\begin{tabular}{lcccccc}
\hline Parameter & $x$ & $T(\mathrm{~h})$ & $\Delta t(\mathrm{~h})$ & $C_{0}$ & $C_{1}$ & $C_{2}$ \\
\hline Value & 0.25 & 3 & 3 & 0.2 & 0.6 & 0.2 \\
\hline
\end{tabular}

the flood process can be obtained after the dam-break flood routes from the Houziyan reservoir to the inflow section of the downstream Changheba reservoir. The maximum flows at the inflow section of the Changheba reservoir are shown in Figure 5, and a typical flood process line is shown in Figure 7. The calculation parameters for the Muskingum method can be found in Table 6 .

Figure 5 shows that if the Houziyan reservoir undergoes a dam break, then the higher the water level in the Houziyan reservoir, the larger the maximum flow. Furthermore, Figure 7 shows that the reservoir discharge increases suddenly when the dam break occurs. After the dam-break flood propagates to downstream Changheba reservoir, the maximum flows are reduced but the shape of the flood process line is basically unchanged.

3.4.2. Conditional Probability Calculation. Based on the maximum inflow flood peak series at the Changheba reservoir coming from the dam-break flood from the Houziyan reservoir, the statistical parameters for the inflow flood, and the flow results subject to various probabilities, can be obtained after fitting the data to a P-III curve (Table 7). Then, further MATLAB simulations and calculations can be carried out to yield the conditional probability that the Changheba reservoir suffers dam overtopping due to the dam-break flood from the Houziyan reservoir (results in Table 8).

As can be seen from Table 8, when the Changheba reservoir is at a normal (check) water level, the conditional probability of the dam overtopping due to a dam-break flood from the Houziyan reservoir is 0.8075 (0.8981). It is clear that a dam break from the Houziyan reservoir induces a large risk that the dam in the Changheba reservoir will overtop; that is, the risk that both reservoirs collapse is relatively large. Also, we can see that the higher the water level in the Changheba 

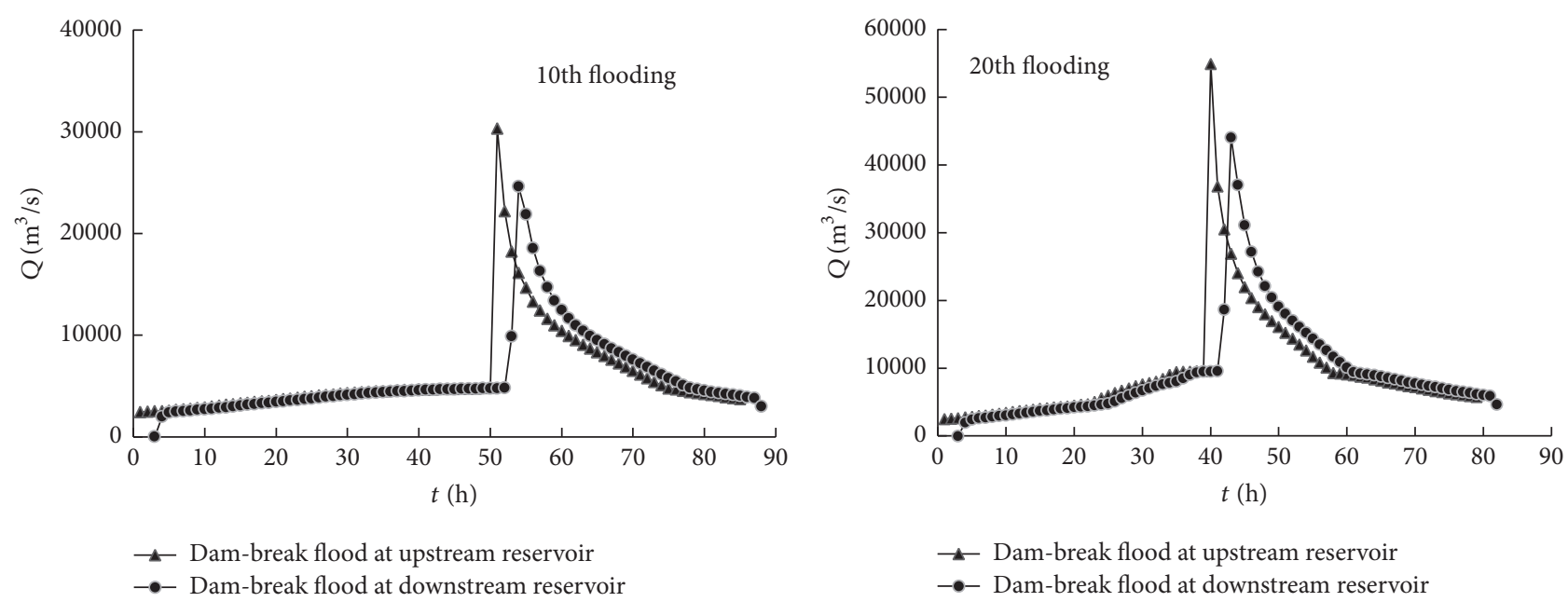

FIGURE 7: Typical flood process lines before and after dam break at the Houziyan reservoir and at the inflow section of the Changheba reservoir.

TABLE 7: Statistical parameters for the dam-break flood at the Changheba reservoir and the designed flood results.

\begin{tabular}{lccccccccc}
\hline \multirow{2}{*}{ Item } & \multicolumn{3}{c}{ Statistical parameter } & \multicolumn{4}{c}{ Designed $P$ value } \\
& Mean & $C_{v}$ & $C_{s} / C_{v}$ & $1 \%$ & $2 \%$ & $5 \%$ & $10 \%$ & $20 \%$ & $50 \%$ \\
\hline$Q_{\max }\left(\mathrm{m}^{3} / \mathrm{s}\right)$ & 31740 & 0.4 & 1 & 64650 & 60200 & 53770 & 48320 & 42020 & 30910 \\
\hline
\end{tabular}

TABLE 8: Simulation parameters and conditional probabilities that the Changheba reservoir dam will overtop due to a dam-break flood from the Houziyan reservoir.

\begin{tabular}{ccccccccc}
\hline \multirow{2}{*}{ Reservoir } & $\begin{array}{c}\text { Simulation } \\
\text { time, } N\end{array}$ & $\begin{array}{c}\text { Probability } \\
\text { interval, } \Delta P\end{array}$ & \multicolumn{2}{c}{$\begin{array}{c}\text { Adjusted water level } \\
\text { Case }\end{array}$} & $\begin{array}{c}\text { Value }(\mathrm{m}) \\
\text { dam, } m \text { (times) }\end{array}$ & $\begin{array}{c}\text { Overtopping } \\
\text { frequency, } P=m / N\end{array}$ & $\begin{array}{c}\text { Overtopping probability } \\
\text { Probability }\end{array}$ & $\Delta P * P$ \\
\hline \multirow{2}{*}{ Changheba } & 10000 & $0 \sim 1$ & Normal & 1690 & 8075 & 0.8075 & $P\left(O_{B} \mid F_{O}\right)$ & 0.8075 \\
& 10000 & $0 \sim 1$ & Check & 1694.6 & 8981 & 0.8981 & $P\left(O_{B} \mid F_{O}\right)$ & 0.8981 \\
\hline
\end{tabular}

reservoir, the greater the risk of the dam overtopping due to the dam-break flood.

\subsection{Risk Analysis for Reservoir Collapse under the Combined} Action of Flood and Landslide Surge. Here, we choose two sets of typical cases for the Houziyan and Changheba reservoirs. The upstream natural flood peak flow is at the designed flood flow, and the reservoir is either at the normal or check water level. Both reservoirs are considered to be at risk of overtopping due to landslide surge. The probability results for dam overtopping in the Houziyan and Changheba reservoirs are shown in Table 9. The two typical cases mentioned above for the two reservoirs are combined into four cases (labeled I-IV). The probability results for two reservoir collapses for the various combinations of typical cases, and the posterior probability results, are shown in Table 10 and Figure 8.

From Table 9, we can see there is little difference between the probabilities that a single reservoir dam will overtop in the four cases when the two reservoirs are under the combined action of flood and landslide surge (all are of the order of $10^{-3}$ ). Once again, the higher the water level in the reservoir is, the greater the probability that a single reservoir dam will overtop. Obviously, the probability of dam overtopping under the combined action of flooding and landslide surge is much larger than that resulting from flooding alone. As shown in Table 10 and Figure 8, dam-break flooding from the Houziyan reservoir increases the probability of the Changheba reservoir dam overtopping by a factor of almost two. This shows that the chance that a dam-break flood results in the Changheba reservoir dam overtopping is relatively large. In addition, for the various combinations of typical cases, the higher the water level in a reservoir, the greater the probability of the Changheba reservoir dam overtopping and the greater the joint probability. The joint probabilities of the two reservoirs collapsing under the combined action of flood and landslide surge shown in Table 10 are very small (of the order of $10^{-15}$ ). The posterior probability results indicate that there is little difference between the risk of the Changheba reservoir dam overtopping due to dam-break flooding from the Houziyan reservoir and that from the combined action of interval flooding and landslide surge in the Changheba reservoir.

\section{Conclusions}

We conclude the following:

(1) The probability that the dams in the Houziyan and Changheba reservoirs overtop due to a single flood 


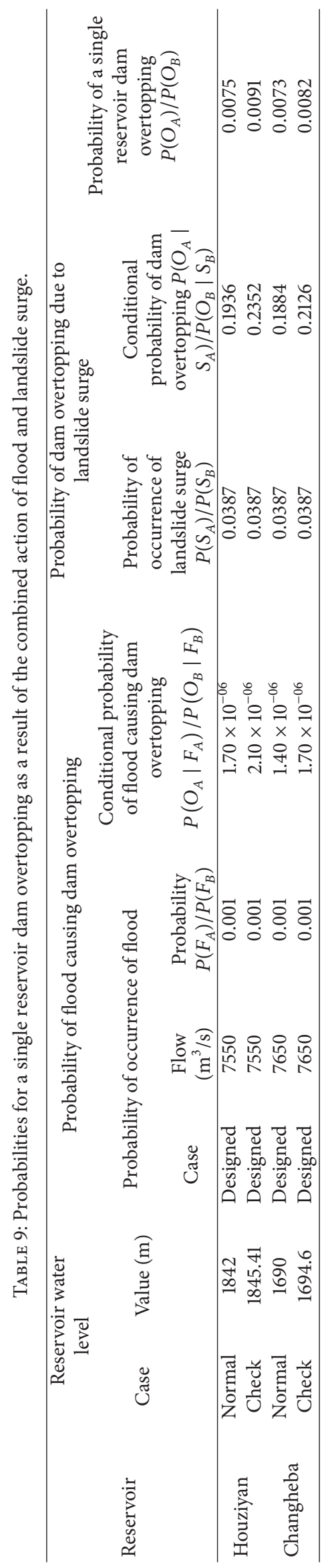




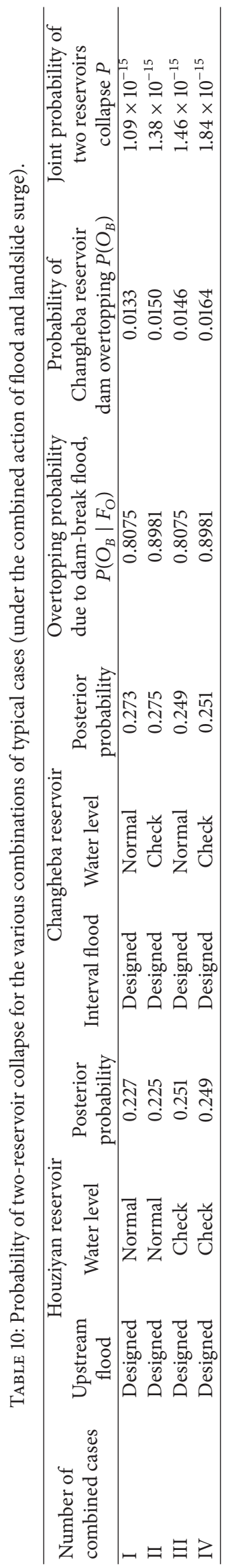



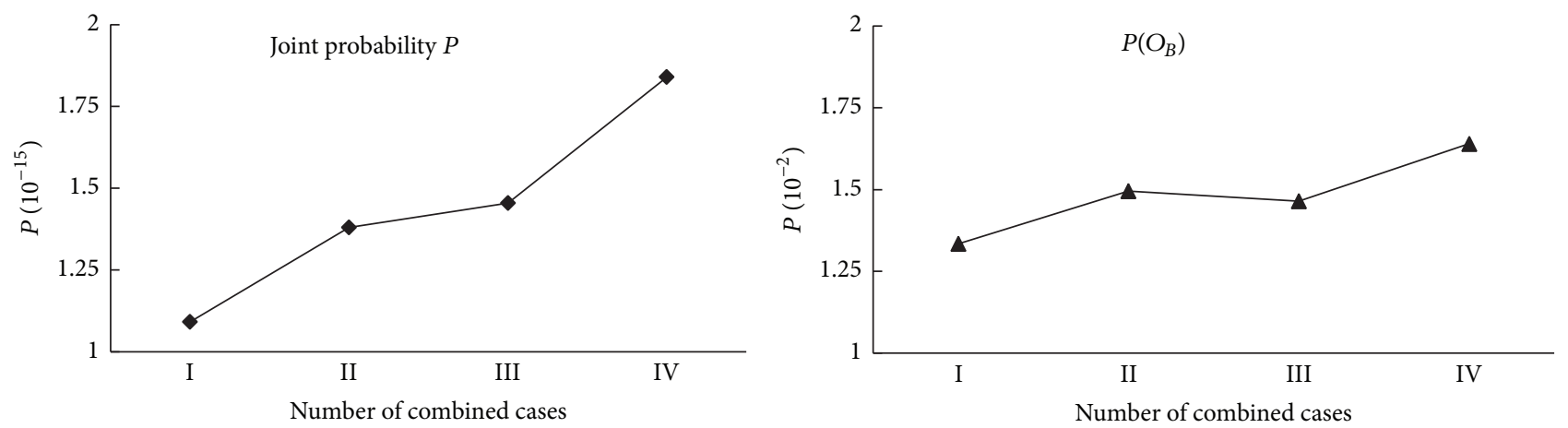

FIGURE 8: The probabilities that the two reservoirs collapse for the four combined cases and for the combined action of flood and landslide surge.

action is very small, with a magnitude of the order of $10^{-6}$. The risk of overtopping due to a landslide surge occurring in one of the reservoirs is relatively large. The conditional probability that dam overtopping will occur due to landslide surge in the Houziyan and Changheba reservoirs (at their normal water levels) is about 0.2. If the reservoir level is higher, however, the overtopping probability will be greater.

(2) The conditional probability of the Changheba reservoir dam overtopping due to dam-break flooding from the Houziyan reservoir is 0.808 when the Changheba reservoir is at its normal level (and 0.898 if it is at its check level). Such dam-break flooding nearly doubles the probability of the dam in the Changheba reservoir overtopping. Thus, the risk of the dam overtopping in the Changheba reservoir due to dam-break flooding from the Houziyan reservoir is relatively large.

(3) The joint probability that the two reservoirs will collapse under the combined action of flooding and landslide surge is very small. For various combinations of typical cases, the probability of such an event was found to be of the order of $10^{-15}$.

(4) Combining Bayesian network theory with stochastic Monte Carlo simulation is an effective method for calculating probabilities and analyzing the risk associated with a single reservoir dam overtopping and for investigating whether multiple cascade reservoirs will collapse under the combined action of various risks and working conditions. This study may constitute a firm basis for providing useful technical support with respect to risk prevention and control in reservoirs in the future.
Abbreviations
$F_{A}$ : Upstream natural flooding of reservoir $A$
$F_{B}$ : Interval flooding, coming from the area between reservoirs $A$ and $B$
$F_{O}$ : Dam-break flooding from reservoir $A$
$S_{A}$ : Landslide surge in reservoir $A$
$S_{B}$ : Landslide surge in reservoir $B$

$O_{A}: \quad$ Dam overtopping in reservoir $A$

$O_{B}$ : $\quad$ Dam overtopping in reservoir $B$

$P\left(O_{A} \mid F_{A}\right)$ : Conditional probability of dam overtopping in reservoir $A$ due to flooding

$P\left(O_{B} \mid F_{B}\right)$ : Conditional probability of dam overtopping in reservoir $B$ due to flooding

$P\left(O_{B} \mid F_{O}\right)$ : Conditional probability of dam overtopping in reservoir $B$ due to dam-break flooding from reservoir $A$

$P\left(F_{A}\right)$ : $\quad$ Prior probability of occurrence of flooding in reservoir $A$

$P\left(F_{B}\right): \quad$ Prior probability of occurrence of interval flooding

$P\left(F_{O}\right): \quad$ Probability of occurrence of dam-break flooding $\left(P\left(O_{A}\right)=P\left(F_{O}\right)\right)$

$P\left(S_{A}\right)$ : $\quad$ Probability of occurrence of landslide

surge in reservoir $A$

$P\left(S_{B}\right): \quad$ Probability of occurrence of landslide surge in reservoir $B$

$P\left(O_{A}\right): \quad$ Probability of occurrence of dam overtopping in reservoir $A$

$P\left(O_{B}\right): \quad$ Probability of occurrence of dam overtopping in reservoir $B$

$P\left(O_{A} \mid S_{A}\right)$ : Conditional probability of dam overtopping in reservoir $A$ due to a landslide surge

$P\left(O_{B} \mid S_{B}\right)$ : Conditional probability of dam overtopping in reservoir $B$ due to a landslide surge.

\section{Competing Interests}

The authors declare that they have no competing interests.

\section{Acknowledgments}

This study was sponsored by the National Key Basic Research and Development Program of China (Grant no. 2013CB036401) and the Natural Science Foundation of China (Grant no. 20130181110045). The authors are also very grateful to the Dadu River Basin Management Company for the provision of data. 


\section{References}

[1] F. Ashkar and J. Rousselle, "Design discharge as a random variable: a risk study," Water Resources Research, vol. 17, no. 3, pp. 577-591, 1981.

[2] J. K. Vrijling and H. J. Verhagen, Probabilistic Design of Hydraulic Structures, Delft University of Technology, Delft, The Netherlands, 2005.

[3] W. Hu, M.-S. Zhang, and L.-F. Zhu, "Research on prediction methods of surges induced by landslides in the Three Gorges reservoir area of the Yellow river," Springer International Publishing, vol. 32, no. 6, pp. 861-867, 2014.

[4] P.-Z. Lin, X. Liu, and J.-M. Zhang, "The simulation of a landslide-induced surge wave and its overtopping of a dam using a coupled ISPH model," Engineering Applications of Computational Fluid Mechanics, vol. 9, no. 1, pp. 432-444, 2015.

[5] Y. Y. Bayraktarli, J. Ulfkjaer, U. Yazgan et al., "On the application of Bayesian probabilistic networks for earthquake risk management," in Proceedings of the 9th International Conference on Structural Safety and Reliability, G. Augusti, G. I. Schuller, and M. Ciampoli, Eds., pp. 3505-3512, Mill Press, 2005.

[6] M. H. Faber, I. B. Kroon, E. Kragh, D. Bayly, and P. Decosemaeker, "Risk assessment of decommissioning options using Bayesian networks," Journal of Offshore Mechanics and Arctic Engineering, vol. 124, no. 4, pp. 231-238, 2002.

[7] D. Straub, "Natural hazards risk assessment using Bayesian networks," in Proceedings of the 9th International Conference on Structural Safety and Reliability (ICOSSAR '05), G. Augusti, G. I. Schuller, and M. Ciampoli, Eds., pp. 2509-2516, Millpress, Rome, Italy, June 2005.

[8] M. Holick, "Reliability and risk assessment of buildings under fire design situation," in Proceedings of the 9th International Conference on Structural Safety and Reliability, G. Augusti, G. I. Schuller, and M. Ciampoli, Eds., pp. 3237-3242, Mill Press, 2005.

[9] R.-Z. Xie, Dam Break Hydraulics, Shandong Science and Technology Press, Jinan, China, 1990.

[10] Y.-L. Fu, "Deze reservoir's security risk analysis affected by dam breaking of Shangyou rrservoir," China Rural Water and Hydropower, vol. 11, pp. 102-105, 2011.

[11] M. Balá, M. Danácová, J. Szolgay, M. Baláž, and M. Danáčová, "On the use of the Muskingum method for the simulation of flood wave movements," Slovak Journal of Civil Engineering, vol. 13, no. 3, pp. 14-20, 2010. 


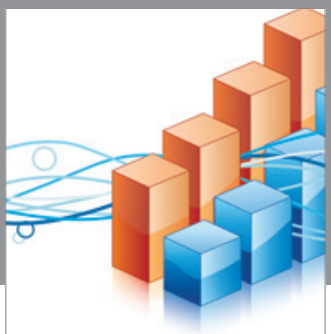

Advances in

Operations Research

vatem alat4

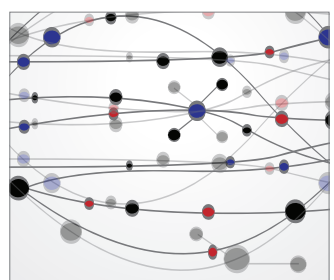

\section{The Scientific} World Journal
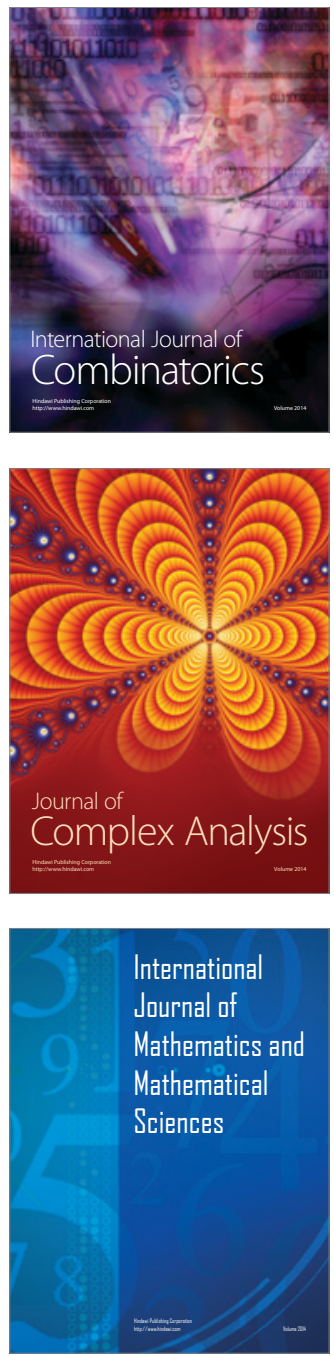
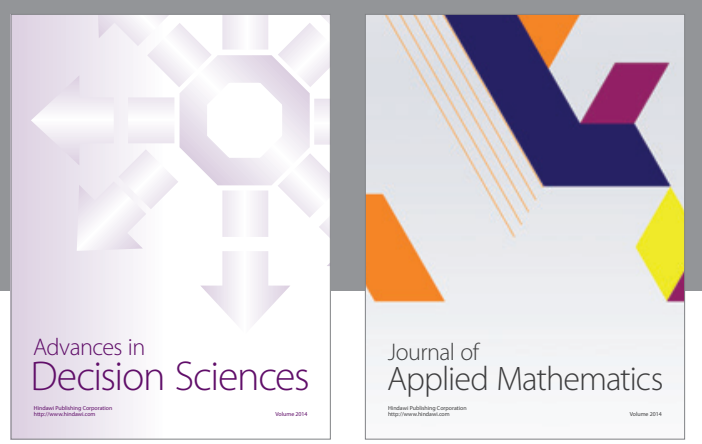

Algebra

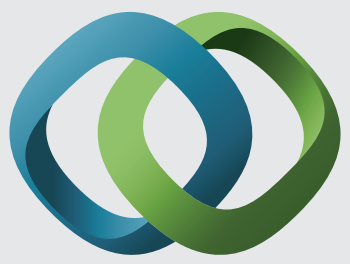

\section{Hindawi}

Submit your manuscripts at

http://www.hindawi.com
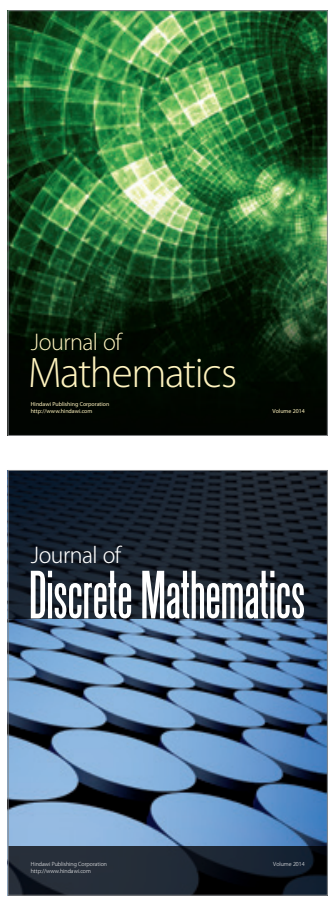

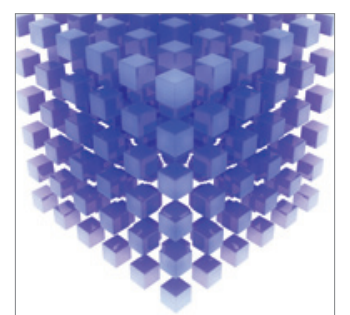

Mathematical Problems in Engineering
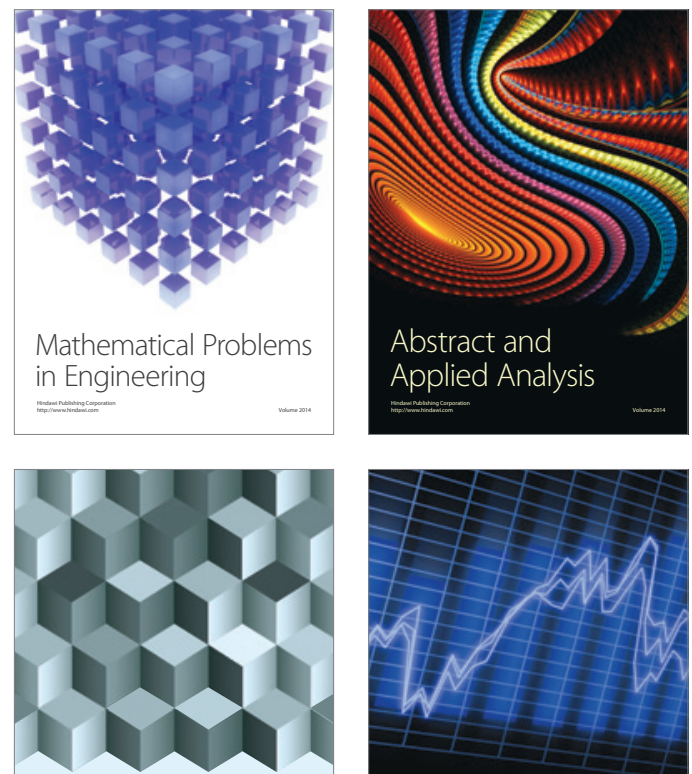

Journal of

Function Spaces

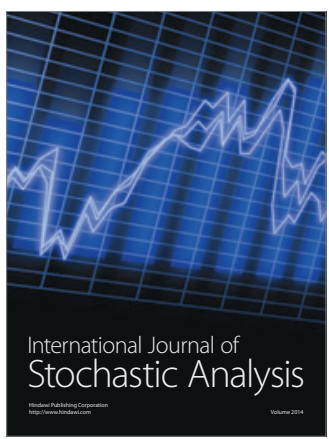

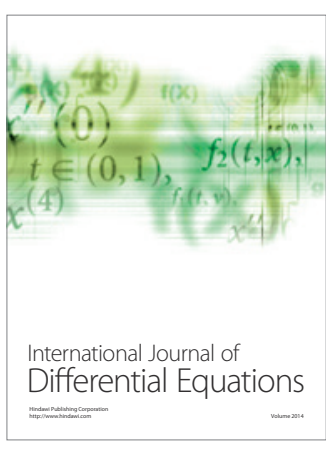
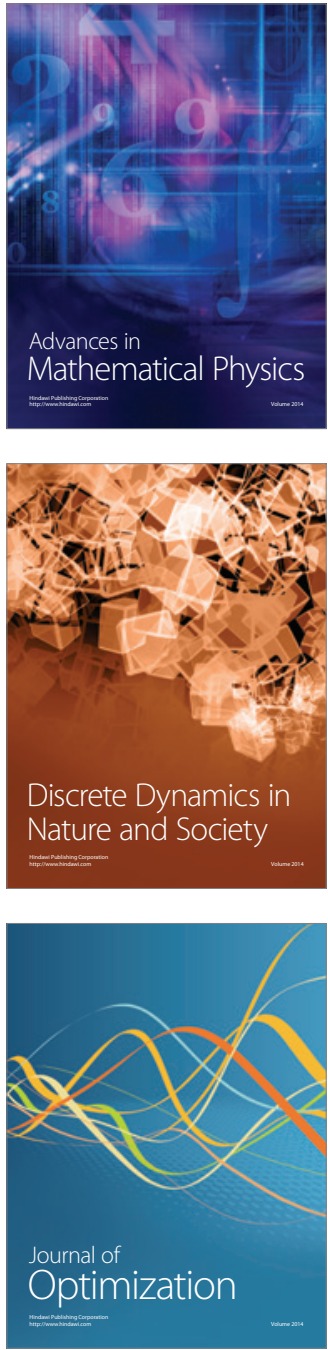